\title{
Acute post-exercise change in blood pressure and exercise training response in patients with coronary artery disease
}

\section{Antti M. Kiviniemi ${ }^{1,2}$, Arto J. Hautala ${ }^{1}$, Jaana J. Karjalainen ${ }^{2}$, Olli-Pekka Piira ${ }^{2}$, Samuli Lepojärvi ${ }^{2}$, Olavi Ukkola ${ }^{2}$, Heikki V. Huikuri' ${ }^{2}$ and Mikko P. Tulppo ${ }^{1,3 *}$}

${ }^{1}$ Department of Exercise and Medical Physiology, Verve Research, Oulu, Finland

${ }^{2}$ Medical Research Center, University of Oulu, Oulu University Hospital, Oulu, Finland

${ }^{3}$ Department of Applied Sciences, London South Bank University, London, UK

Edited by:

Jaakko Hartiala, Turku University

Hospital, Finland

Reviewed by:

Tomi Petteri Laitinen, University of

Eastern Finland and Kuopio

University Hospital, Finland

Matti Ilari Luotolahti, Turku

University Hospital, Finland

*Correspondence:

Mikko P. Tulppo, Department of Exercise and Medical Physiology, Verve Research, Kasarmintie 13, PO Box 404, Fl-90130 Oulu, Finland e-mail:mikko.tulppo@verve.fi
We tested the hypothesis that acute post-exercise change in blood pressure (BP) may predict exercise training responses in $\mathrm{BP}$ in patients with coronary artery disease (CAD). Patients with $\mathrm{CAD}$ ( $n=116$, age $62 \pm 5$ years, 85 men) underwent BP assessments at rest and during 10-min recovery following a symptom-limited exercise test before and after the 6-month training intervention (one strength and 3-4 aerobic moderate-intensity exercises weekly). Post-exercise change in systolic BP (SBP) was calculated by subtracting resting SBP from lowest post-exercise SBP. The training-induced change in resting SBP was $-2 \pm$ $13 \mathrm{mmHg}(p=0.064)$, ranging from -42 to $35 \mathrm{mmHg}$. Larger post-exercise decrease in SBP and baseline resting SBP predicted a larger training-induced decrement in SBP ( $\beta=$ 0.46 and $\beta=-0.44$, respectively, $p<0.001$ for both). Acute post-exercise decrease in SBP provided additive value to baseline resting SBP in the prediction of training-induced change in resting SBP ( $R^{2}$ from 0.20 to $\left.0.26, p=0.002\right)$. After further adjustments for other potential confounders (sex, age, baseline body mass index, realized training load), post-exercise decrease in SBP still predicted the training response in resting SBP $(\beta=$ $0.26, p=0.015)$. Acute post-exercise change in SBP was associated with training-induced change in resting SBP in patients with $C A D$, providing significant predictive information beyond baseline resting SBP.

Keywords: ischemic heart disease, hypertension, arterial pressure, training adaptation, acute exercise, exercise testing, autonomic function

\section{INTRODUCTION}

Elevated BP is an important therapeutic target in cardiovascular risk management in coronary artery disease (CAD) (Yap et al., 2007). In addition to medical treatment, lifestyle interventions, including exercise training, are of pivotal importance in treatment of increased BP (Eckel et al., 2014). Exercise-based rehabilitation decreases mortality and resting BP by an average of $\sim 3 \mathrm{mmHg}$ in patients with $\mathrm{CAD}$, but many patients receive no benefits to BP from training (Hagberg et al., 2000; Rice et al., 2002; Taylor et al., 2004), which limits the effectiveness of exercise training in prevention and treatment of hypertension in CAD.

Rationale for the effects of exercise training on BP relies partly on acute BP reduction after a single exercise-often termed postexercise hypotension - which typically constitutes BP decreases of 5-20 mmHg for hours after the exercise (Macdonald et al., 2000; Halliwill, 2001; Jones et al., 2007; Eicher et al., 2010). Strong relationship has been observed between acute postexercise hypotension and chronic reductions in BP among

Abbreviations: $\triangle \mathrm{BP}_{\text {PostEx }}$, acute post-exercise change in blood pressure; $\mathrm{BMI}$, body mass index; $\mathrm{BP}$, blood pressure; $\mathrm{CAD}$, coronary artery disease; $\mathrm{DBP}$, diastolic blood pressure; HF, high frequency $(0.15-0.4 \mathrm{~Hz})$; HR, heart rate; LF, low frequency $(0.04-0.15 \mathrm{~Hz})$; MET, metabolic equivalent; SBP, systolic blood pressure; TRIMP, training impulse; $\mathrm{VO}_{2 \text { peak }}$, peak oxygen consumption. pre-hypertensive individuals, suggesting that acute post-exercise hypotension might well identify achievable decrease in BP by exercise training (Liu et al., 2012). However, Liu et al. did not report to what extent acute post-exercise hypotension predicts training-induced decrements in BP beyond baseline BP (Liu et al., 2012), which often determines both acute and chronic effects of exercise on BP (Taylor et al., 2010). It is not known whether acute post-exercise change in $\mathrm{BP}$ is related to training outcome in resting $\mathrm{BP}$ among patients with $\mathrm{CAD}$ when baseline resting $\mathrm{BP}$ is considered. We hypothesized that acute post-exercise change in BP may be related to training-induced changes in resting $\mathrm{BP}$ in $\mathrm{CAD}$, providing significant information beyond baseline resting $\mathrm{BP}$.

\section{MATERIALS AND METHODS SUBJECTS AND STUDY PROTOCOL}

The present study is part of the ARTEMIS study (Innovation to Reduce Cardiovascular Complications of Diabetes at the Intersection) in Division of Cardiology at Oulu University Hospital (Oulu, Finland) and Department of Exercise and Medical Physiology at Verve (Oulu, Finland). The ARTEMIS study is registered at ClinicalTrials.gov, Record 1539/31/06. The study was performed according to the Declaration of Helsinki, the local research ethics committee of the Northern Ostrobothnia 
Hospital District approved the protocol, and all the subjects gave their written informed consent.

Patients with angiographically documented CAD $(n=146)$ and willing to participate exercise training intervention were recruited from the ARTEMIS database, observing the exclusion criteria described elsewhere in details (Kiviniemi et al., 2013). Patients with pre-diabetes, verified by fasting glucose and oral glucose tolerance test (Alberti and Zimmet, 1998), were excluded because of the main focus of the ARTEMIS project. $\mathrm{CAD}$ and its severity were assessed by syntax score (Sianos et al., 2005). Left ventricular mass index and systolic (ejection fraction) and diastolic function (ratio of early transmitral flow velocity to early diastolic mitral annulus velocity) were measured with two-dimensional tissue Doppler echocardiography (Vivid 7, GE Healthcare, Wauwatosa, WI, USA). Urine and fasting blood samples were obtained for analysis of renal function, inflammation, lipid and glucose metabolism. These clinical examinations were conducted only at the baseline.

The patients were invited to the Department of Exercise and Medical Physiology at Verve (Oulu, Finland), where further measurements were conducted before and after the intervention. The tests were performed at the same time of day in pre- and posttraining conditions when subjects were refrained from eating and caffeine for $3 \mathrm{~h}$ and from exercise and alcohol for $24 \mathrm{~h}$ before the tests but did not cease their medications. The patients underwent measurements at supine rest and during passive head-up tilt to determine resting BP and cardiac autonomic function. After 10-15 min of supine rest, the tilt protocol started with supine recording $(5 \mathrm{~min})$ followed by passive tilt $\left(80^{\circ}, 5 \mathrm{~min}\right)$, while the patients breathing spontaneously. Blood pressure was measured twice during both phases (at 1:30 and 4:00) of the protocol (Tango, SunTech, Raleigh, NC, USA) and the average value of the two measurements was used to represent BP for each phase, with $\mathrm{BP}$ in the supine position representing resting BP. R-R intervals were recorded at an accuracy of $1 \mathrm{~ms}$ (Polar R-R recorder, Polar Electro Oy, Kempele, Finland).

The patients performed a symptom-limited maximal exercise test on a bicycle (Monark Ergomedic 839 E, Monark Exercise Ab, Vansbro, Sweden) for assessment of cardiorespiratory fitness and $\mathrm{BP}$ during the exercise and recovery. The test was started at $30 \mathrm{~W}$ and the work rate was increased by $15 \mathrm{~W}$ in men and $10 \mathrm{~W}$ in women every minute until voluntary exhaustion or ST segment depression $>0.2 \mathrm{mV}$ on ECG (GE Healthcare, CAM-14, Freiburg, Germany). After termination of the test, the patients lay down and remained still and silent for $10 \mathrm{~min}$. Blood pressure was measured at 2-min intervals during the test and recovery, where the first $\mathrm{BP}$ reading was obtained $1 \mathrm{~min}$ after exhaustion (Tango, SunTech, Raleigh, NC, USA). The highest 1-min mean value of oxygen consumption (M909 Ergospirometer, Medikro, Kuopio, Finland) was taken to express peak oxygen uptake $\left(\mathrm{VO}_{2 \text { peak }}\right)$. Exercise capacity was calculated in metabolic equivalents (METs) from the mean workload during the last minute of the test. Relative exercise capacity was expressed as a percentage of the predicted exercise capacity, which was calculated as $18-(0.15 \cdot$ age $)$ for men and 14.7-(0.13.age) for women (Kim et al., 2007). Acute post-exercise change in BP was quantified by subtracting the mean of two resting $\mathrm{BP}$ measurements measured before the exercise test from the lowest $\mathrm{BP}$ value during 10 -min supine recovery after symptomlimited exercise both measured in a supine position $\left(\triangle \mathrm{BP} \mathrm{PostEx}_{\mathrm{P}}=\right.$ resting $\mathrm{BP}-$ minimum post-exercise $\mathrm{BP}$ ).

\section{HEART RATE VARIABILITY ANALYSIS}

Heart rate variability was edited and analyzed in Hearts program (Heart Signal Co., Oulu, Finland). Ectopic beats and artifacts were removed from the tachogram based on visual inspection ( $<10 \%$ for each recording). In addition to mean heart rate (HR), autoregressive spectral analysis (model order 20) was performed to analyze the low- (LF, $0.04-0.15 \mathrm{~Hz}$ ) and high-frequency (HF, $0.15-0.4 \mathrm{~Hz}$ ) power of R-R interval oscillation from both entire 5min phases (Taskforce, 1996). The power spectrum densities are presented in absolute units transformed into natural logarithm $\left(\ln \mathrm{ms}^{2}\right)$. The LF/HF ratio was also calculated.

\section{TRAINING INTERVENTION}

Training during the first 3 months included three HR-controlled (Polar F1, Polar Electro Oy, Kempele, Finland) endurance exercises (30 min, $50-60 \%$ of the HR reserve) and one strength exercise $(30 \mathrm{~min})$ weekly. The patients were allowed to choose the mode of endurance exercise which was typically walking, jogging or cycling. Strength exercise was circuit training including major muscle groups at moderate intensity $(2 * 7$ sets, $\geq 10$ repetitions/set). After 3 months, the training included two endurance exercises at $50-60 \%$ and two at $60-70 \%$ of the HR reserve (both $30 \mathrm{~min}$ ), and one strength training session ( $30 \mathrm{~min})$. The patients received a diary with prescribed training days, along with duration and intensity (HR) of the exercises, and resting days and marked the realized training mode, duration, and mean HR in the diary. The patients were contacted after 1 and 3 months by a specialist in sports medicine to check their progress. Weekly target and realized training loads were calculated as the mean training impulse (TRIMP) (Morton et al., 1990). In calculating the target TRIMP for endurance training, the intensity was an average of prescribed exercise HR ( 55 or $65 \%$ of the HR reserve) and in strength training, on $90 \%$ of the target HR of light endurance exercise, based on our previous experience (Hautala et al., 2006). Thirty patients terminated the study due to personal reasons, a lack of motivation, or musculoskeletal problems, thus, the final analysis consisted of 116 patients (Table 1).

\section{STATISTICAL ANALYSIS}

The data are presented as the mean $\pm S D$. The changes in antihypertensive drug treatment during the intervention were coded as follows: $-2=$ terminated, $-1=$ decreased dose, $0=$ no change, $1=$ increased dose, and $2=$ start of new medication. The paired t-test was used to assess the effects of training on measured variables, except for time to minimum post-exercise BP which was tested by Wilcoxon test due to its non-Gaussian distribution. Univariate linear regression was employed to determine the relationship between the change in resting BP and baseline variables and their changes during the intervention as well as to assess the determinants of $\triangle B P_{\text {PostEx }}$ at the baseline. Multivariate linear regression was used to assess the additive value of $\triangle \mathrm{BP}$ PostEx to baseline resting $\mathrm{BP}$ in the prediction of training response in resting BP (model 1). The most significant determinants of 
Table 1 | Characteristics of the study group.

\begin{tabular}{|c|c|}
\hline & $n=116$ \\
\hline Men, n & $87(75 \%)$ \\
\hline Age, years & $62 \pm 5$ \\
\hline Hypertension, n & $81(70 \%)$ \\
\hline Current smokers, $\mathrm{n}$ & $9(8 \%)$ \\
\hline CCS class $\geq 2, n$ & $18(16 \%)$ \\
\hline $\mathrm{T} 2 \mathrm{D}, \mathrm{n}$ & $53(46 \%)$ \\
\hline T2D duration, months & $70 \pm 84$ \\
\hline \multicolumn{2}{|l|}{ HISTORY OF AMI } \\
\hline NSTEMI, n & $31(27 \%)$ \\
\hline STEMI n & $22(19 \%)$ \\
\hline \multicolumn{2}{|l|}{ REVASCULARIZATION } \\
\hline $\mathrm{PCl}, \mathrm{n}$ & $74(64 \%)$ \\
\hline CABG, $n$ & $26(22 \%)$ \\
\hline \multicolumn{2}{|l|}{ ECHOCARDIOGRAPHY } \\
\hline LVEF, \% & $66 \pm 8$ \\
\hline LVMI & $98 \pm 22$ \\
\hline$E / E^{\prime}$ & $9.5 \pm 3.0$ \\
\hline \multicolumn{2}{|l|}{ CORONARY ANGIOGRAPHY } \\
\hline Syntax score & $3.6 \pm 5.0$ \\
\hline \multicolumn{2}{|l|}{ MEDICATION } \\
\hline Oral antidiabetics, $n$ & $41(35 \%)$ \\
\hline Insulin, n & $5(4 \%)$ \\
\hline Beta blockers, n & $103(89 \%)$ \\
\hline ACEI or ARB, $n$ & $67(58 \%)$ \\
\hline Anticholesterol agents, $\mathrm{n}$ & $107(92 \%)$ \\
\hline Anticoagulants, $n$ & $113(97 \%)$ \\
\hline Calcium antagonists, $\mathrm{n}$ & $19(16 \%)$ \\
\hline Nitrates, n & $27(23 \%)$ \\
\hline Diuretics, $n$ & $37(32 \%)$ \\
\hline \multicolumn{2}{|l|}{ LABORATORY ANALYSES } \\
\hline Fasting glucose, $\mathrm{mmol} \cdot \mathrm{L}^{-1}$ & $6.0 \pm 1.1$ \\
\hline $\mathrm{HbA1c}, \%$ & $6.2 \pm 0.7$ \\
\hline Insulin, $\mathrm{mU} \cdot \mathrm{L}^{-1}$ & $14.0 \pm 10.2$ \\
\hline Total cholesterol, $\mathrm{mmol} \cdot \mathrm{L}^{-1}$ & $4.0 \pm 0.8$ \\
\hline LDL cholesterol, mmol. $\mathrm{L}^{-1}$ & $2.4 \pm 0.7$ \\
\hline HDL cholesterol, $\mathrm{mmol} \cdot \mathrm{L}^{-1}$ & $1.2 \pm 0.3$ \\
\hline Triglycerides, $\mathrm{mmol} \cdot \mathrm{L}^{-1}$ & $1.5 \pm 0.8$ \\
\hline $\mathrm{hs}-\mathrm{CRP}, \mathrm{mg} \cdot \mathrm{L}^{-1}$ & $1.9 \pm 3.0$ \\
\hline Creatinine, $\mu \mathrm{mol} \cdot \mathrm{L}^{-1}$ & $74 \pm 14$ \\
\hline Albumin, $\mathrm{mg} \cdot \mathrm{L}^{-1}$ & $10.4 \pm 20.7$ \\
\hline $\mathrm{ACR}, \mathrm{mg} \cdot \mathrm{mmol}^{-1}$ & $1.2 \pm 2.3$ \\
\hline
\end{tabular}

Values are the number of subjects (proportion) or means $\pm S D$. CCS, Canadian Cardiovascular Society angina classification; T2D, type 2 diabetes; AMI, acute myocardial infarction; NSTEMI, non-ST segment elevation myocardial infarction; STEMI, ST segment elevation myocardial infarction; PCl, percutaneus coronary intervention; $C A B G$, coronary artery by-pass grafting; $L V E F$, left ventricular ejection fraction; $L V M I$, left ventricular mass index; $E / E^{\prime}$, ratio of early transmitral flow velocity to early diastolic mitral annulus velocity, ACEl, angiotensin conversion enzymes inhibitor; $A R B$, angiotensin receptor blocker; HbA1c, glycated hemoglobin; LDL, low-density lipoprotein; HDL, high-density lipoprotein; hs-CRP, high-sensitivity $C$-reactive protein; $A C R$, albumin-creatinine ratio. training responses in resting $\mathrm{BP}$ were analyzed by multivariate linear regression, where baseline resting $\mathrm{BP}$, baseline $\triangle \mathrm{BP}_{\mathrm{PostEx}}$, age, sex, baseline body mass index (BMI), realized training load, and other relevant variables and their changes, specifically associated with training responses in SBP and DBP, were entered as independent factors (model 2). Multivariate linear regression was also employed to assess the most significant determinants of $\triangle \mathrm{BP}_{\text {PostEx }}$ at the baseline by entering the significant variables in univariate analysis as independent factors. The data were analyzed using IBM SPSS Statistics 21 (IBM Corporation, Somers, New York). A $p<0.05$ was considered statistically significant.

\section{RESULTS}

The mean TRIMP was $262 \pm 155$ /week, which was $129 \pm 74 \%$ of the target TRIMP (median: 110\%; interquartile range: $85-161 \%$ ). Training frequencies and durations were $3.4 \pm 1.1,2.8 \pm 1.0$ and $0.7 \pm 0.4$ sessions/week; and $38 \pm 15,47 \pm 16$, and $27 \pm 13 \mathrm{~min}$ for all exercises, endurance and strength exercises, respectively. The most significant changes were observed in BMI, waist-hip ratio, resting DBP, exercise capacity, and $\mathrm{VO}_{2 \text { peak }}$ (Table 2). A reduction of $\geq 2 \mathrm{mmHg}$ in SBP was observed in $46 \%$ of the patients, whereas $59 \%$ of the patients obtained DBP reduction of $\geq 1 \mathrm{mmHg}$ during the intervention. No significant changes were observed in antihypertensive medication.

In addition to baseline resting SBP, $\triangle \mathrm{SBP}_{\mathrm{PostEx}}$ was strongly related to training response in SBP (Table 3 ). The traininginduced change in resting DBP was associated with baseline resting DBP, $\triangle \mathrm{DBP}_{\text {PostEx }}$, syntax score, nitrate medication, albumin, albumin-creatinine ratio, $\mathrm{LF} / \mathrm{HF}$ ratio, more strongly during passive tilt (Table 3 ), and with the change in relative $\mathrm{VO}_{2 \text { peak }}$ $(\beta=-0.20, p=0.036)$. The changes in BMI, antihypertensive medication, and heart rate variability were not associated with training outcome in SBP or DBP.

$\triangle \mathrm{SBP}_{\mathrm{PostEx}}$ provided significant additive value to baseline resting SBP in the prediction of training response in resting SBP $\left(\mathrm{R}^{2}\right.$ from 0.20 to $0.26, p=0.002$, Figure 1 ). In multivariate linear regression, the final model explained $30 \%$ of training response in SBP. $\triangle$ SBP PostEx $(\beta=0.26, p=0.015)$ and baseline resting SBP $(\beta=-0.26, p=0.010)$ were significant predictors of training outcome in SBP, while sex, age, baseline BMI, and realized training load were not ( $p>0.05$ for all).

$\triangle \mathrm{DBP}_{\text {PostEx }}$ did not improve the prediction of training response in resting DBP after adjustment for baseline resting DBP $\left(\mathrm{R}^{2}\right.$ from 0.30 to $0.31, p=0.420$ ). In the final model of training response in DBP, baseline values of resting $\mathrm{DBP}(\beta=-0.33$, $p=0.001)$ and $\mathrm{LF} / \mathrm{HF}$ ratio during passive tilt $(\beta=-0.17$, $p=0.041)$ and the change in relative $\mathrm{VO}_{2 \text { peak }}(\beta=-0.18, p=$ 0.028 ) remained as significant factors, explaining $47 \%$ of training response in resting DBP. Sex, age, baseline BMI, training load, severity of CAD (syntax score), nitrate medication, renal function, and $\triangle \mathrm{DBP} \mathrm{P}_{\mathrm{PostEx}}$ were not significantly associated with training outcome in DBP in the multivariate regression $(p>0.05$ for all).

The determinants of $\triangle \mathrm{BP}_{\mathrm{PostEx}}$ at the baseline are presented in Table 3. In multivariate analysis, resting SBP $(\beta=-0.54, p<$ $0.001)$, type 2 diabetes $(\beta=0.18, p=0.041)$ and $\mathrm{BMI}(\beta=0.19$, 
Table 2 | Effects of exercise training on anthropometric, blood pressure, heart rate variability, and exercise test variables.

\begin{tabular}{|c|c|c|c|}
\hline & Pre & Post & $p$-Value \\
\hline Body mass index, $\mathrm{kg} \cdot \mathrm{m}^{-2}$ & $28.2 \pm 3.9$ & $27.9 \pm 3.8$ & 0.003 \\
\hline Waist-hip ratio & $0.97 \pm 0.07$ & $0.96 \pm 0.07$ & 0.001 \\
\hline \multicolumn{4}{|l|}{ SUPINE REST } \\
\hline SBP, mmHg & $137 \pm 17$ & $134 \pm 16$ & 0.064 \\
\hline $\mathrm{DBP}, \mathrm{mmHg}$ & $82 \pm 8$ & $80 \pm 7$ & 0.024 \\
\hline $\mathrm{HR}$, bpm & $56 \pm 8$ & $56 \pm 8$ & 0.269 \\
\hline$L F, \ln m s^{2}$ & $5.6 \pm 1.2$ & $5.5 \pm 1.1$ & 0.356 \\
\hline $\mathrm{HF}, \mathrm{In} \mathrm{ms}^{2}$ & $5.3 \pm 1.2$ & $5.3 \pm 1.1$ & 0.789 \\
\hline LF/HF-ratio & $1.9 \pm 1.9$ & $1.8 \pm 2.2$ & 0.767 \\
\hline \multicolumn{4}{|l|}{ PASSIVE TILT } \\
\hline $\mathrm{SBP}, \mathrm{mmHg}$ & $127 \pm 20$ & $126 \pm 18$ & 0.333 \\
\hline $\mathrm{DBP}, \mathrm{mmHg}$ & $77 \pm 10$ & $77 \pm 10$ & 0.277 \\
\hline $\mathrm{HR}$, bpm & $61 \pm 8$ & $61 \pm 9$ & 0.732 \\
\hline$L F, \ln m s^{2}$ & $5.4 \pm 1.1$ & $5.3 \pm 1.1$ & 0.801 \\
\hline$H F, \ln m s^{2}$ & $4.9 \pm 1.2$ & $5.0 \pm 1.3$ & 0.444 \\
\hline LF/HF-ratio & $2.2 \pm 1.6$ & $2.2 \pm 2.1$ & 0.927 \\
\hline \multicolumn{4}{|l|}{ EXERCISE TEST } \\
\hline EC, METs & $7.4 \pm 1.9$ & $7.6 \pm 2.0$ & $<0.001$ \\
\hline$E C, \%$ & $90 \pm 22$ & $93 \pm 22$ & $<0.001$ \\
\hline $\mathrm{VO}_{2 \text { peak, }} \mathrm{L} \cdot \mathrm{min}^{-1}$ & $2.00 \pm 0.55$ & $2.06 \pm 0.57$ & $<0.001$ \\
\hline $\mathrm{VO}_{2 \text { peak, }} \mathrm{mL} \cdot \mathrm{kg}^{-1} \cdot \mathrm{min}^{-1}$ & $24.6 \pm 6.7$ & $25.6 \pm 7.0$ & $<0.001$ \\
\hline $\mathrm{HR}_{\text {peak }}, \mathrm{bpm}$ & $134 \pm 19$ & $135 \pm 19$ & 0.502 \\
\hline $\mathrm{SBP}_{\text {peak }}, \mathrm{mmHg}$ & $209 \pm 28$ & $208 \pm 29$ & 0.671 \\
\hline $\mathrm{DBP}_{\text {peak }}, \mathrm{mmHg}$ & $99 \pm 13$ & $99 \pm 12$ & 0.638 \\
\hline$\Delta \mathrm{SBP}_{\text {PostEx }}, \mathrm{mmHg}$ & $-13 \pm 14$ & $-12 \pm 14$ & 0.238 \\
\hline$\Delta \mathrm{DBP}_{\text {PostEx }}, \mathrm{mmHg}$ & $-11 \pm 7$ & $-10 \pm 7$ & 0.263 \\
\hline Time $_{\text {PostExSBP}}, \min$ & $8 \pm 1$ & $8 \pm 1$ & 0.646 \\
\hline Time $_{\text {PostExDBP, }}$ min & $7 \pm 2$ & $6 \pm 3$ & 0.359 \\
\hline
\end{tabular}

Values are or means $\pm S D$. SBP, systolic blood pressure; DBP, diastolic blood pressure; $H R$, heart rate; $L F$, low frequency power of heart rate variability; $H F$, high frequency power of heart rate variability; $E C$, exercise capacity; $V_{2 p e a k}$, peak oxygen consumption; PostEx, post-exercise.

$p=0.022)$ remained as significant factors underlying $\Delta \mathrm{SBP}_{P o s t E x}$, whereas sex, low-density lipoprotein cholesterol and absolute $\mathrm{VO}_{2 \text { peak }}$ did not $(p>0.05$ for all). Resting DBP $(\beta=-0.51$, $p<0.001)$ and triglycerides $(\beta=0.17, p=0.043)$ were significant determinants of $\triangle \mathrm{DBP} \mathrm{PostEx}_{\mathrm{x}}$ in multivariate analysis but type 2 diabetes, history of myocardial infarction, $\mathrm{HR}_{\text {peak }}$, oral antidiabetic medication and glycated hemoglobin were not $(p>0.05$ for all).

\section{DISCUSSION}

The main finding of the present study was that acute post-exercise change in SBP predicts training outcome in resting SBP beyond basal resting SBP in CAD and other potent determinants of training response in resting SBP. In contrast, acute post-exercise change in DBP was not as strongly related to training response in resting DBP. Interestingly, training outcome in DBP was associated with the baseline $\mathrm{LF} / \mathrm{HF}$ ratio and improved $\mathrm{VO}_{2 \text { peak }}$. The present results suggest that acute post-exercise change in BP contributes to the inter-individual variation in SBP responses to
Table 3 | Univariate determinants of acute post-exercise change in blood pressure and training-induced change in resting blood pressure at the baseline.

\begin{tabular}{|c|c|c|c|c|}
\hline & $\Delta \mathrm{SBP}_{\text {PostEx }}$ & $\Delta \mathrm{DBP}_{\text {PostEx }}$ & $\Delta \mathrm{SBP}_{\text {Training }}$ & $\Delta \mathrm{DBP}_{\text {Training }}$ \\
\hline Male gender & $0.20 *$ & 0.07 & 0.17 & -0.07 \\
\hline Age & -0.01 & 0.12 & -0.18 & -0.03 \\
\hline Body mass index & $0.19 *$ & 0.16 & 0.08 & -0.14 \\
\hline Waist-hip ratio & 0.05 & 0.03 & 0.07 & -0.14 \\
\hline Hypertension & -0.09 & -0.05 & -0.09 & -0.06 \\
\hline Current smoking & -0.12 & -0.06 & 0.10 & -0.05 \\
\hline CCS class $\geq 2$ & 0.01 & 0.04 & 0.13 & -0.01 \\
\hline $\mathrm{T} 2 \mathrm{D}$ & $0.20 *$ & $0.20 *$ & 0.11 & -0.04 \\
\hline $\begin{array}{l}\text { History of } \\
\text { myocardial infarction }\end{array}$ & 0.08 & $0.20 *$ & 0.07 & 0.12 \\
\hline $\begin{array}{l}\text { History of } \mathrm{PCl} \\
\text { or } \mathrm{CABG}\end{array}$ & 0.08 & 0.10 & 0.09 & 0.10 \\
\hline LVEF & 0.00 & -0.03 & 0.05 & 0.12 \\
\hline LVMI & 0.06 & 0.07 & 0.09 & -0.14 \\
\hline $\mathrm{E} / \mathrm{E}^{\prime}$ & -0.04 & -0.07 & 0.04 & -0.00 \\
\hline Syntax score & -0.01 & -0.02 & -0.08 & $-0.30 * *$ \\
\hline \multicolumn{5}{|l|}{ MEDICATION } \\
\hline Oral antidiabetics & 0.17 & $0.19 *$ & 0.07 & 0.01 \\
\hline Insulin & -0.04 & -0.10 & 0.13 & 0.02 \\
\hline Beta blockers & 0.09 & 0.13 & 0.02 & 0.12 \\
\hline ACEI or ARB & 0.01 & -0.02 & 0.05 & 0.04 \\
\hline $\begin{array}{l}\text { Anticholesterol } \\
\text { agents }\end{array}$ & -0.04 & 0.05 & -0.08 & 0.08 \\
\hline Anticoagulants & -0.17 & -0.07 & -0.09 & -0.01 \\
\hline Calcium antagonists & 0.06 & 0.06 & 0.06 & 0.06 \\
\hline Nitrates & 0.15 & 0.02 & 0.12 & $-0.23^{*}$ \\
\hline Diuretics & -0.11 & 0.01 & -0.01 & 0.05 \\
\hline \multicolumn{5}{|c|}{ LABORATORY ANALYSES } \\
\hline Fasting glucose & 0.15 & 0.12 & 0.06 & -0.07 \\
\hline $\mathrm{HbA1c}$ & 0.10 & $0.20 *$ & -0.04 & -0.02 \\
\hline Insulin & 0.02 & 0.01 & 0.04 & 0.05 \\
\hline Total cholesterol & -0.17 & -0.08 & -0.06 & -0.06 \\
\hline LDL cholesterol & $-0.20^{*}$ & -0.09 & -0.02 & -0.03 \\
\hline HDL cholesterol & -0.10 & -0.12 & 0.00 & 0.06 \\
\hline Triglycerides & 0.11 & $0.21 *$ & -0.08 & -0.07 \\
\hline hs-CRP & 0.04 & 0.00 & 0.06 & 0.08 \\
\hline Creatinine & 0.26 & 0.07 & -0.08 & -0.16 \\
\hline Albumin & -0.01 & 0.03 & -0.13 & $-0.30 * *$ \\
\hline ACR & -0.06 & -0.02 & -0.15 & $-0.31 * *$ \\
\hline \multicolumn{5}{|l|}{ SUPINE REST } \\
\hline SBP & $-0.55^{* * *}$ & $-0.38 * * *$ & $-0.44 * * *$ & $-0.28 * *$ \\
\hline DBP & $-0.37 * * *$ & $-0.54 * * *$ & $-0.27 * *$ & $-0.55^{* * *}$ \\
\hline HR & -0.09 & -0.15 & -0.10 & -0.14 \\
\hline LF & -0.12 & -0.09 & 0.01 & -0.09 \\
\hline $\mathrm{HF}$ & -0.07 & -0.08 & 0.09 & -0.01 \\
\hline LF/HF-ratio & -0.09 & -0.09 & -0.10 & $-0.20^{*}$ \\
\hline \multicolumn{5}{|l|}{ PASSIVE TILT } \\
\hline SBP & $-0.38 * * *$ & $-0.32 * *$ & $-0.20^{*}$ & -0.17 \\
\hline DBP & $-0.32 * *$ & $-0.35 * * *$ & $-0.24 *$ & $-0.30 * *$ \\
\hline HR & -0.04 & -0.08 & -0.07 & -0.12 \\
\hline LF & $-0.23^{*}$ & -0.16 & -0.06 & -0.07 \\
\hline $\mathrm{HF}$ & $-0.20^{*}$ & -0.08 & 0.02 & 0.02 \\
\hline LF/HF-ratio & -0.06 & $-0.20^{*}$ & -0.11 & $-0.24 * *$ \\
\hline
\end{tabular}


Table 3 | Continued

\begin{tabular}{|c|c|c|c|c|}
\hline & $\Delta \mathrm{SBP}_{\text {PostEx }}$ & $\Delta D_{B P}$ PostEx & $\Delta \mathrm{SBP}_{\text {Training }}$ & $\Delta \mathrm{DBP}_{\text {Training }}$ \\
\hline \multicolumn{5}{|l|}{ EXERCISE TEST } \\
\hline EC, METs & 0.07 & -0.13 & 0.05 & -0.08 \\
\hline EC, \% & -0.03 & -0.13 & -0.08 & -0.07 \\
\hline $\mathrm{VO}_{2 \text { peak }}, \mathrm{L} \cdot \mathrm{min}^{-1}$ & $0.19 *$ & -0.01 & 0.15 & -0.12 \\
\hline $\begin{array}{l}\mathrm{VO}_{2 \text { peak, }} \\
\mathrm{mL} \cdot \mathrm{kg}^{-1} \cdot \mathrm{min}^{-1}\end{array}$ & 0.08 & -0.12 & 0.07 & -0.08 \\
\hline $\mathrm{HR}_{\text {peak }}$ & -0.10 & $-0.23^{*}$ & -0.10 & -0.08 \\
\hline $\mathrm{SBP}_{\text {peak }}$ & -0.06 & -0.17 & -0.11 & -0.13 \\
\hline $\mathrm{DBP}_{\text {peak }}$ & -0.18 & -0.10 & $-0.22^{*}$ & -0.02 \\
\hline$\triangle \mathrm{SBP}_{\text {PostEx }}$ & - & $0.56^{* * *}$ & $0.46^{* * *}$ & $0.21 *$ \\
\hline$\triangle \mathrm{DBP}_{\text {PostEx }}$ & $0.56 * * *$ & - & 0.15 & $0.35^{* * *}$ \\
\hline
\end{tabular}

Values are standardized coefficients ( $\beta$ ) from univariate linear regression. CCS, Canadian Cardiovascular Society angina classification; T2D, type 2 diabetes; $P C l$, percutaneus coronary intervention; $C A B G$, coronary artery by-pass grafting; $L V E F$, left ventricular ejection fraction; $L V M I$, left ventricular mass index; $E / E^{\prime}$, ratio of early transmitral flow velocity to early diastolic mitral annulus velocity; ACEl, angiotensin conversion enzymes inhibitor; ARB, angiotensin receptor blocker; HbA1c, glycated hemoglobin; $L D L$, low-density lipoprotein; $H D L$, high-density lipoprotein; hs-CRP, high-sensitivity $C$-reactive protein; $A C R$, albumin-creatinine ratio; SBP, systolic blood pressure; DBP, diastolic blood pressure; $H R$, heart rate; $L F$, low frequency power of heart rate variability; $H F$, high frequency power of heart rate variability; $E C$, exercise capacity; $V O_{2 p e a k}$, peak oxygen consumption; PostEx, post-exercise. ${ }^{*} p<0.05,{ }^{* *} p<0.01,{ }^{* * *} p<$ 0.001 .

aerobic-based exercise training in CAD but to a lesser extent to training responses in DBP.

As expected (Hagberg et al., 2000; Rice et al., 2002; Liu et al., 2012), exercise training responses in BP involved large interindividual variation in patients with CAD. Our principal finding was that acute post-exercise change in SBP predicted training outcome in resting SBP beyond baseline resting SBP in CAD. After inclusion of other determinants of training response in SBP, acute post-exercise change in SBP still predicted the training response in resting SBP. The present findings support the rationale connecting the acute and chronic SBP-lowering effects of exercise training (Halliwill, 2001; Liu et al., 2012), which was not completely explained by baseline resting SBP. Baseline resting BP must be taken into account in order to minimize the effects of mathematical coupling between acute and chronic BP responses (Taylor et al., 2010). In this light, the previous study by Liu et al. (2012) may have provided overly optimistic results. The correlation between acute post-exercise change in BP and training-induced changes in BP was lower in the present patients with CAD $(\beta=$ 0.46 for SBP) compared with the previous pre-hypertensive group ( $\beta=0.89$ for SBP) (Liu et al., 2012). Greater heterogeneity in the present study population may also explain this lower correlation. Also, Liu et al. assessed acute post-exercise change in BP after typical aerobic exercise (30 min at $65 \%$ of maximal oxygen consumption) (Liu et al., 2012), whereas, in the present study, it was assessed after symptom-limited exercise test. Yet, acute post-exercise change in SBP predicted training outcome in resting SBP after adjustment for baseline resting SBP, suggesting that the present findings could be easily implemented in standard clinical exercise testing. If lesser post-exercise hypotension is observed, more frequent follow-up might be needed in order to tailor exercise training in order to optimize training responses in BP. Different training modalities, including, e.g., larger component of dynamic or isometric resistance training, may prove beneficial in this respect (Cornelissen et al., 2011; Cornelissen and Smart, 2013).

While the acute post-exercise change in SBP predicted the training response in resting SBP, this association was weaker in DBP. It is well-established that arterial stiffness is a major determinant of elevated SBP with advancing age, by augmenting pulse pressure due to loss of elasticity of the arteries (Franklin et al., 1997). While the contribution of systemic vascular resistance to DBP might be larger than to SBP, increased arterial stiffness may actually decrease DBP with advancing age $>50$ years, despite increasing SBP (Franklin et al., 1997). Exercise training decreases arterial stiffness (Joyner, 2000; Tabara et al., 2007), which may be a potent mechanism coupling acute post-exercise change in SBP and training-induced outcome in SBP-especially when the relationship between acute and the chronic effects of exercise were dissociated between SBP and DBP. While Tabara et al. did not observe decreases in arterial stiffness after acute aerobic exercise, a larger acute decrease in arterial stiffness was associated with a larger decrease in arterial stiffness after 6 months of exercise training among elderly individuals (Tabara et al., 2007).

While training outcome in DBP was most strongly determined by baseline resting $\mathrm{DBP}$, increased $\mathrm{LF} / \mathrm{HF}$ ratio, an estimate of sympathovagal balance (Malliani et al., 1991), and the traininginduced increase in $\mathrm{VO}_{2 \text { peak }}$ were associated with decreased DBP with training. The finding on LF/HF ratio suggests that baseline sympathetic predominance may predict the larger traininginduced decrease in DBP. While DBP may be more associated with systemic vascular resistance-where the neural sympathetic component plays an important role-it could be hypothesized that patients with sympathetic predominance may have greater potential to decrease neural sympathetic activity. While the changes in LF/HF ratio were not associated with training outcome in DBP, contribution of autonomic balance to BP responses remains unclear. Interestingly, an improved relative $\mathrm{VO}_{2 \text { peak }}$ was also associated with larger decrements in DBP. However, the changes in absolute $\mathrm{VO}_{2 \text { peak }}$ and exercise capacity were not related to training-induced decreases in DBP, which is why the present results are inconsistent in this respect.

In conclusion, acute post-exercise change in $\mathrm{BP}$ predicted training outcome in resting SBP and provided significant information beyond baseline resting SBP in patients with CAD. However, post-exercise hypotension in DBP was not as strongly related to training response in resting DBP, which was most evidently explained by baseline resting DBP. The present findings help to understand the determinants underlying the interindividual variation in $\mathrm{BP}$ responses to aerobic-based exercise training in CAD.

\section{LIMITATIONS}

Control group would have improved the present research setting. Despite the well-controlled BP measurements, it would have been beneficial to establish how reproducibility of BP measurements 

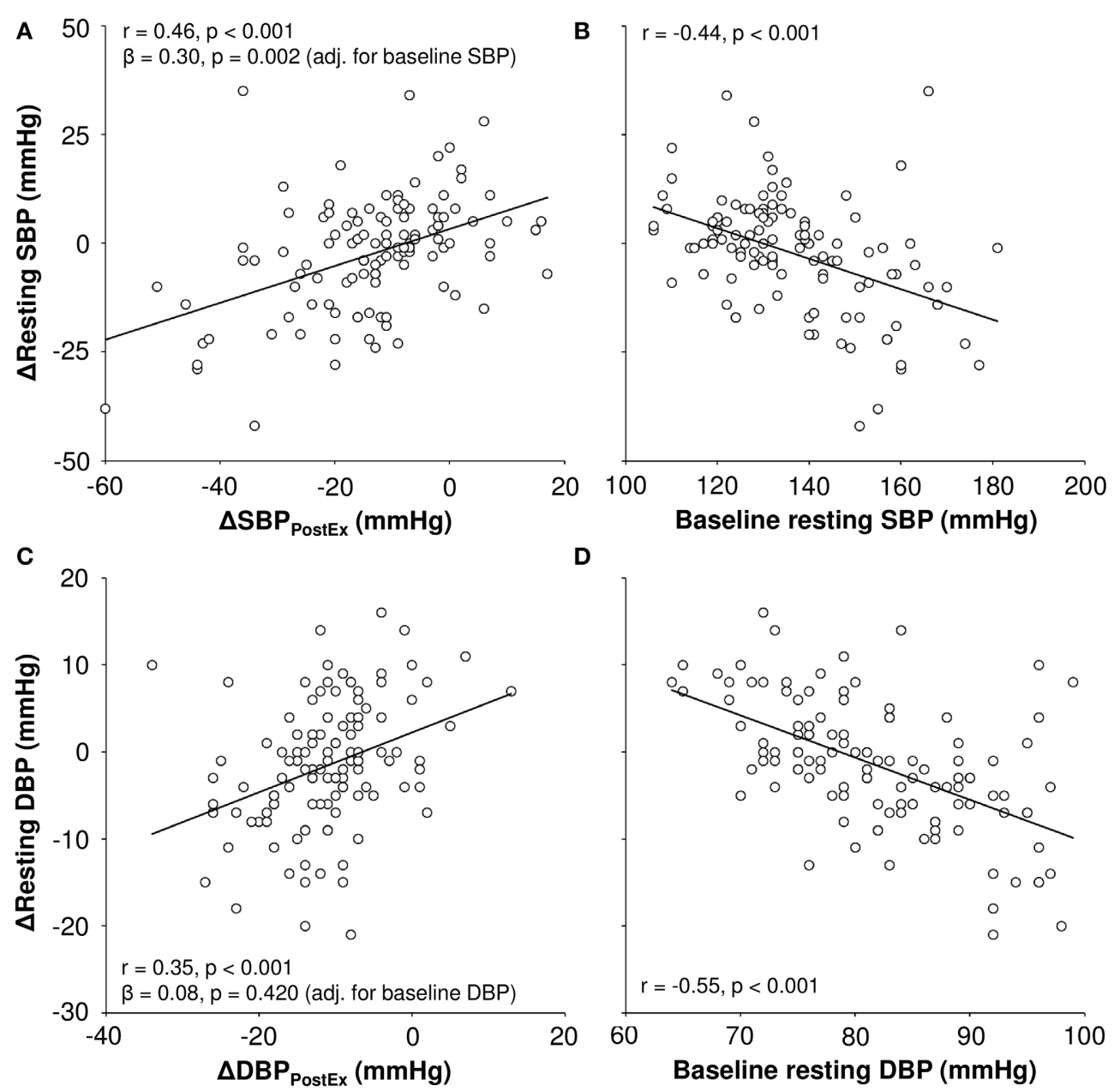

FIGURE 1 | Correlation of acute post-exercise change $\left(\Delta \mathrm{BP}_{\mathrm{Post} \mathrm{x}}\right)$ in blood pressure and baseline resting blood pressure to exercise training-mediated changes in resting systolic (SBP, A,B) and diastolic blood pressure (DBP, C,D).

contributes to the present observations. A possible white-coat effect might have occurred in some cases in laboratory BP assessments (Grassi et al., 1999). Also, due the considerable daily variation in BP, ambulatory measurements might have been beneficial. The changes in the resting $\mathrm{BP}$ and cardiorespiratory fitness at group level were only modest despite the well-realized training load. However, the training frequency turned out to be lower than currently recommended for the patients with CAD (Piepoli et al., 2010), which may explain these modest responses. Medical treatment, e.g., statin medication ( $92 \%$ of patients), may also have compromised the training responses in cardiorespiratory fitness (Mikus et al., 2013). Acute post-exercise change in BP was evaluated from the symptom-limited exercise stress test. Ultimately, we cannot establish how typically the realized exercise elicited acute post-exercise changes in BP. However, it is plausible to assume that the intensity and total workload of the exercise was in proportion to the patients' exercise capacity. Also, the present results rely on a rather short period of acute recovery when establishing acute post-exercise change in BP. As measured and expected, however, significant post-exercise hypotension was observed during the 10-min recovery (Macdonald et al., 1999). Finally, measures of systemic vascular resistance, arterial stiffness, and endothelial function might have provided more mechanistic insight to the present observations.

\section{AUTHOR CONTRIBUTIONS}

Antti M. Kiviniemi: Design of the work, acquisition, analysis and interpretation of data, drafting the work, final approval of work and its integrity. Arto J. Hautala: Design of the work, acquisition, analysis and interpretation of data, revision and final approval of work and its integrity. Jaana J. Karjalainen: Design of the work, acquisition, analysis and interpretation of data, revision and final approval of work and its integrity. Olli-Pekka Piira: Design of the work, acquisition and interpretation of data, revision and final approval of work and its integrity. Samuli Lepojärvi: Design of the work, acquisition and interpretation of data, revision and final approval of work and its integrity. Olavi Ukkola: Design of the work, interpretation of data, revision and final approval of work and its integrity. Heikki V. Huikuri: Design of the work, interpretation of data, revision and final approval of work and its 
integrity. Mikko P. Tulppo: Design of the work, interpretation of data interpretation of data, revision and final approval of work and its integrity.

\section{GRANTS}

This study was supported by funding from the Finnish Technology Development Centre (Helsinki, Finland), Polar Electro Oy (Kempele, Finland), Ab HUR Oy (Kokkola, Finland), the Academy of Finland (Helsinki, Finland) and the Finnish Foundation of Cardiovascular Research.

\section{ACKNOWLEDGMENTS}

Research personnel at the Division of Cardiology, University Hospital of Oulu, are gratefully acknowledged.

\section{REFERENCES}

Alberti, K. G., and Zimmet, P. Z. (1998). Definition, diagnosis and classification of diabetes mellitus and its complications. Part 1: diagnosis and classification of diabetes mellitus provisional report of a WHO consultation. Diabet. Med. 15, 539-553.

Cornelissen, V. A., Fagard, R. H., Coeckelberghs, E., and Vanhees, L. (2011). Impact of resistance training on blood pressure and other cardiovascular risk factors: a meta-analysis of randomized, controlled trials. Hypertension 58, 950-958. doi: 10.1161/HYPERTENSIONAHA.111.177071

Cornelissen, V. A., and Smart, N. A. (2013). Exercise training for blood pressure: a systematic review and meta-analysis. J. Am. Heart Assoc. 2:e004473. doi: 10.1161/JAHA.112.004473

Eckel, R. H., Jakicic, J. M., Ard, J. D., De Jesus, J. M., Houston Miller, N., Hubbard, V. S., et al. (2014). 2013 AHA/ACC guideline on lifestyle management to reduce cardiovascular risk: a Report of the American College of Cardiology/American Heart Association Task Force on Practice Guidelines. Circulation 129, S76-S99. doi: 10.1161/01.cir.0000437740.48606.d1

Eicher, J. D., Maresh, C. M., Tsongalis, G. J., Thompson, P. D., and Pescatello, L. S. (2010). The additive blood pressure lowering effects of exercise intensity on post-exercise hypotension. Am. Heart J. 160, 513-520. doi: 10.1016/j.ahj.2010.06.005

Franklin, S. S., Gustin, W. T., Wong, N. D., Larson, M. G., Weber, M. A., Kannel, W. B., et al. (1997). Hemodynamic patterns of age-related changes in blood pressure. The framingham heart study. Circulation 96, 308-315. doi: 10.1161/01.CIR.96.1.308

Grassi, G., Turri, C., Vailati, S., Dell'Oro, R., and Mancia, G. (1999). Muscle and skin sympathetic nerve traffic during the "white-coat" effect. Circulation 100, 222-225. doi: 10.1161/01.CIR.100.3.222

Hagberg, J. M., Park, J. J., and Brown, M. D. (2000). The role of exercise training in the treatment of hypertension: an update. Sports Med. 30, 193-206. doi: 10.2165/00007256-200030030-00004

Halliwill, J. R. (2001). Mechanisms and clinical implications of post-exercise hypotension in humans. Exerc. Sport Sci. Rev. 29, 65-70. doi: 10.1097/00003677200104000-00005

Hautala, A. J., Kiviniemi, A. M., Makikallio, T. H., Kinnunen, H., Nissila, S., Huikuri, H. V., et al. (2006). Individual differences in the responses to endurance and resistance training. Eur. J. Appl. Physiol. 96, 535-542. doi: 10.1007/s00421005-0116-2

Jones, H., George, K., Edwards, B., and Atkinson, G. (2007). Is the magnitude of acute post-exercise hypotension mediated by exercise intensity or total work done? Eur. J. Appl. Physiol. 102, 33-40. doi: 10.1007/s00421-007-0562-0

Joyner, M. J. (2000). Effect of exercise on arterial compliance. Circulation 102, 1214-1215. doi: 10.1161/01.CIR.102.11.1214

Kim, E. S., Ishwaran, H., Blackstone, E., and Lauer, M. S. (2007). External prognostic validations and comparisons of age- and gender-adjusted exercise capacity predictions. J. Am. Coll. Cardiol. 50, 1867-1875. doi: 10.1016/j.jacc.2007. 08.003

Kiviniemi, A. M., Hautala, A. J., Karjalainen, J. J., Piira, O. P., Lepojärvi, S., Tiinanen, S., et al. (2013). Impact of type 2 diabetes on cardiac autonomic responses to sympathetic stimuli in patients with coronary artery disease. Auton. Neurosci. 179, 142-147. doi: 10.1016/j.autneu.2013.08.068
Liu, S., Goodman, J., Nolan, R., Lacombe, S., and Thomas, S. G. (2012). Blood pressure responses to acute and chronic exercise are related in prehypertension. Med. Sci. Sports Exerc. 44, 1644-1652. doi: 10.1249/MSS.0b013e31825408fb

Macdonald, J., Macdougall, J., and Hogben, C. (1999). The effects of exercise intensity on post exercise hypotension. J. Hum. Hypertens. 13, 527-531. doi: 10.1038/sj.jhh.1000866

Macdonald, J. R., Macdougall, J. D., and Hogben, C. D. (2000). The effects of exercise duration on post-exercise hypotension. J. Hum. Hypertens. 14, 125-129. doi: 10.1038/sj.jhh.1000953

Malliani, A., Pagani, M., Lombardi, F., and Cerutti, S. (1991). Cardiovascular neural regulation explored in the frequency domain. Circulation 84, 482-492. doi: 10.1161/01.CIR.84.2.482

Mikus, C. R., Boyle, L. J., Borengasser, S. J., Oberlin, D. J., Naples, S. P., Fletcher, J., et al. (2013). Simvastatin impairs exercise training adaptations. J. Am. Coll. Cardiol. 62, 709-714. doi: 10.1016/j.jacc.2013.02.074

Morton, R. H., Fitz-Clarke, J. R., and Banister, E. W. (1990). Modeling human performance in running. J. Appl. Physiol. 69, 1171-1177.

Piepoli, M. F., Corra, U., Benzer, W., Bjarnason-Wehrens, B., Dendale, P., Gaita, D., et al. (2010). Secondary prevention through cardiac rehabilitation: from knowledge to implementation. A position paper from the Cardiac Rehabilitation Section of the European Association of Cardiovascular Prevention and Rehabilitation. Eur. J. Cardiovasc. Prev. Rehabil. 17, 1-17. doi: 10.1097/HJR.0b013e3283313592

Rice, T., An, P., Gagnon, J., Leon, A. S., Skinner, J. S., Wilmore, J. H., et al. (2002). Heritability of HR and BP response to exercise training in the HERITAGE Family Study. Med. Sci. Sports Exerc. 34, 972-979. doi: 10.1097/00005768200206000-00011

Sianos, G., Morel, M. A., Kappetein, A. P., Morice, M. C., Colombo, A., Dawkins, K., et al. (2005). The SYNTAX Score: an angiographic tool grading the complexity of coronary artery disease. EuroIntervention 1, 219-227.

Tabara, Y., Yuasa, T., Oshiumi, A., Kobayashi, T., Miyawaki, Y., Miki, T., et al. (2007). Effect of acute and long-term aerobic exercise on arterial stiffness in the elderly. Hypertens. Res. 30, 895-902. doi: 10.1291/hypres.30.895

Taskforce. (1996). Task Force of the European Society of Cardiology and the North American Society of Pacing and Electrophysiology. Heart rate variability. Standards of measurement, physiological interpretation, and clinical use. Eur. Heart J. 17, 354-381.

Taylor, C. E., Jones, H., Zaregarizi, M., Cable, N. T., George, K. P., and Atkinson, G. (2010). Blood pressure status and post-exercise hypotension: an example of a spurious correlation in hypertension research? J. Hum. Hypertens. 24, 585-592. doi: 10.1038/jhh.2009.112

Taylor, R. S., Brown, A., Ebrahim, S., Jolliffe, J., Noorani, H., Rees, K., et al. (2004). Exercise-based rehabilitation for patients with coronary heart disease: systematic review and meta-analysis of randomized controlled trials. Am. J. Med. 116, 682-692. doi: 10.1016/j.amjmed.2004.01.009

Yap, Y. G., Duong, T., Bland, J. M., Malik, M., Torp-Pederson, C., Kober, L., et al. (2007). Prognostic value of blood pressure measured during hospitalization after acute myocardial infarction: an insight from survival trials. J. Hypertens. 25, 307-313. doi: 10.1097/HJH.0b013e3280115bae

Conflict of Interest Statement: The authors declare that the research was conducted in the absence of any commercial or financial relationships that could be construed as a potential conflict of interest.

Received: 19 November 2014; paper pending published: 08 December 2014; accepted: 22 December 2014; published online: 12 January 2015.

Citation: Kiviniemi AM, Hautala AJ, Karjalainen JJ, Piira O-P, Lepojärvi S, Ukkola O, Huikuri HV and Tulppo MP (2015) Acute post-exercise change in blood pressure and exercise training response in patients with coronary artery disease. Front. Physiol. 5:526. doi: 10.3389/fphys.2014.00526

This article was submitted to Clinical and Translational Physiology, a section of the journal Frontiers in Physiology.

Copyright (c) 2015 Kiviniemi, Hautala, Karjalainen, Piira, Lepojärvi, Ukkola, Huikuri and Tulppo. This is an open-access article distributed under the terms of the Creative Commons Attribution License (CC BY). The use, distribution or reproduction in other forums is permitted, provided the original author(s) or licensor are credited and that the original publication in this journal is cited, in accordance with accepted academic practice. No use, distribution or reproduction is permitted which does not comply with these terms. 